\title{
PENGARUH ORIENTASI ETIS, EQUITY SENSITIVITY, DAN BUDAYA JAWA TERHADAP PERILAKU ETIS AUDITOR PADA KANTOR AKUNTAN PUBLIK DI YOGYAKARTA
}

\author{
Eni Widiastuti \\ Alumni Prodi Akuntansi Universitas Negeri Yogyakarta \\ eni_widiastuti94@yahoo.co.id \\ Mahendra Adhi Nugroho \\ Jurusan Pendidikan Akuntansi Universitas Negeri Yogyakarta
}

\begin{abstract}
Abstrak: Pengaruh Orientasi Etis, Equity Sensitivity, dan Budaya Jawa terhadap Perilaku Etis Auditor pada Kantor Akuntan Publik di Yogyakarta. Penelitian ini bertujuan untuk mengetahui: (1) pengaruh Orientasi Etis Idealisme terhadap Perilaku Etis Auditor, (2) pengaruh Orientasi Etis Relativisme terhadap Perilaku Etis Auditor, (3) pengaruh Equity Sensitivity terhadap Perilaku Etis Auditor, (4) pengaruh Budaya Jawa terhadap Perilaku Etis Auditor, dan (5) pengaruh Orientasi Etis Idealisme, Orientasi Etis Relativisme, Equity Sensitivity, dan Budaya Jawa terhadap Perilaku Etis Auditor. Populasi penelitian ini adalah seluruh auditor yang bekerja di Kantor Akuntan Publik (KAP) di Yogyakarta. Metode pengumpulan data dengan kuesioner. Uji validitas menggunakan uji korelasi Pearson Product Moment, sedangkan uji reliabilitas menggunakan Conbrach Alpha. Uji asumsi klasik meliputi uji linearitas, uji heteroskedastisitas, dan uji multikolinearitas. Uji hipotesis pada penelitian ini menggunakan analisis regresi sederhana, dan analisis regresi berganda. Hasil penelitian menunjukkan bahwa (1) Terdapat pengaruh Orientasi Etis Idealisme terhadap Perilaku Etis Auditor, (2) Terdapat pengaruh Orientasi Etis Relativisme terhadap Perilaku Etis Auditor, (3) Terdapat pengaruh Equity Sensitivity terhadap Perilaku Etis Auditor, (4) Terdapat pengaruh Budaya Jawa terhadap Perilaku Etis Auditor, (5) Terdapat pengaruh Orientasi Etis Idealisme, Orientasi Etis Relativisme, Equity Sensitivity, dan Budaya Jawa secara simultan terhadap Perilaku Etis Auditor.
\end{abstract}

Kata kunci: Orientasi Etis, Equity Sensitivity, Budaya Jawa, dan Perilaku Etis Auditor.

Abstract: The Influence of Ethical Orientation, Equity Sensitivity, and Javanes Culture on Ethical Behavior of Auditors at Public Accounting Firm in Yogyakarta. The research aims to know: (1) the influence of Ethical Orientation Idealism on Ethical Behavior of Auditors, (2) the influence of Ethical Orientation Relativism on Ethical Behavior of Auditors, (3) the influence of Equity Sensitivity on Ethical Behavior of Auditors, (4) the influence of Javanes Culture on Ethical Behavior of Auditors, and (5) the influence of Ethical Orientation idealism, Ethical Orientation Relativism, Equity Sensitivity, and Javanes Culture on Ethical Behavior of Auditors. The population of this research are Auditors who work at Public Accounting Firm (KAP) in Yogyakarta. In collecting data, the researcher used questionnaires as the method. Furthermore, the researcher used Pearson Product Moment to test the validity and Conbrach Alpha to test the reliability. The classical assumption test includes linearity test, heteroscedasticity test, and multicollinearity test. To test the hypothesis, the researcher used simple regression analysis and multiple regression analysis. The result of this research showed that: (1) there was influence of Ethical Orientation Idealism on Ethical Behavior of Auditors, (2) there was influence of Ethical Orientation Relativism on Ethical Behavior of Auditors, (3) there was influence of Equity Sensitivity on Ethical Behavior of Auditors, (4) there was influence of Javanes Culture on Ethical Behavior of Auditors, (5) there was 


\section{JURNAL NOMINAL / VOLUME IV NOMOR 1 / TAHUN 2015}

influence of Ethical Orientation idealism, Ethical Orientation Relativism, Equity Sensitivity, and Javanes Culture on Ethical Behavior of Auditors.

Keywords: Ethical Orientation, Equity Sensitivity, Javanes Culture, and Ethical Behavior of Auditor

\section{PENDAHULUAN}

Auditor merupakan salah satu profesi yang mempunyai peran penting bagi dunia bisnis. Eksistensi auditor dari waktu ke waktu juga semakin diakui. Auditor melakukan audit bukan semata-mata hanya untuk kepentingan kliennya, tetapi juga untuk pihak lain yang berkepentingan terhadap laporan keuangan auditan dan auditor pun juga dituntut untuk memiliki kompetensi yang memadai.

Auditor mendapat kepercayaan dari publik untuk membuktikan kewajaran laporan keuangan yang disajikan oleh suatu perusahaan. Karena pentingnya peran auditor tersebut, maka setiap auditor dituntut untuk mempunyai pengetahuan, pemahaman dan penerapan etika secara memadai dalam pelaksanaan pekerjaan profesionalnya.

Kesadaran etika dan sikap profesional harus ada dalam diri seorang auditor mengingat bahwa profesi tersebut sangat membutuhkan kepercayaan masyarakat terhadap kualitas audit yang diberikan. Adanya pengaruh etika yang ada dalam diri seorang auditor akan mempengaruhi perilaku auditor dan etis tidaknya keputusan yang diambil. Orientasi etis merupakan bagaimana pandangan seseorang mengenai etika itu sendiri. Perilaku etis seseorang akan berpengaruh dalam pengambilan keputusan ketika menghadapi dilema etis. Forsyth (1980) mengatakan bahwa orientasi etika atau nilai-nilai etika dikendalikan oleh dua karakteristik yaitu idealisme dan relativisme.

Idealisme merupakan orientasi etika yang mengacu pada sejauh mana seseorang percaya bahwa konsekuensi dari tindakan yang dilakukan dapat terjadi tanpa melanggar nilai-nilai moral. Sedangkan relativisme adalah orientasi etika yang mengacu pada penolakan terhadap nilai-nilai (aturan) moral universal yang membimbing perilaku.

Peran dan tanggung jawab auditor, sebenarnya sudah diatur dalam Standar Profesional Akuntan Publik (SPAP) yang ditetapkan oleh Ikatan Akuntan Indonesia (IAI) atau Statement on Auditing Standards (SASs) yang dikeluarkan oleh Auditing Standard Boards (SAB). Begitu juga kode etik auditor dituangkan dalam Kode Etik Akuntan Indonesia (Ihyaul, 2009).

Beberapa perusahaan pernah jatuh karena kegagalan bisnis mereka yang dikaitkan dengan kegagalan auditor dalam 


\section{JURNAL NOMINAL / VOLUME IV NOMOR 1 / TAHUN 2015}

memberikan opini. Issue mengenai etika auditor sangat menarik sejak munculnya kasus Enron yang melibatkan salah satu kantor akuntan publik The Big Five Arthur Andersen, selain itu juga ada kasus Xerox dan Walt Disney. Di Indonesia, terdapat kasus PT Telkom, kasus KPMG-Siddharta \& Harsono dan masih banyak kasus-kasus pelanggaran etika serupa yang terjadi di Indonesia walaupun dengan bentuk yang berbeda. Akibat dari beberapa kasus yang menimpa auditor tersebut, pengguna laporan keuangan mulai mempertanyakan eksistensi auditor yang seharusnya mampu menyelesaikan pekerjaannya tanpa melakukan pelanggaran etika.

Penelitian mengenai faktor-faktor yang memengaruhi sikap dan perilaku etis seseorang salah satunya adalah equity sensitivity atau prinsip keadilan. Huseman (1987) menjelaskan bahwa individu dapat dikategorikan sebagai benevolent (givers), equity sensitivity, dan entitleds (getters).

Bila dikaikan dengan keadilan, ternyata aspek moral dari budaya yang lebih berbicara. Kemampuan seorang profesional dalam memahami persoalan etika juga sangat dipengaruhi oleh lingkungan dimana dia berada. Dominasi budaya dalam sebuah masyarakat akan berpengaruh terhadap perilaku individu. Pendapat umum menyatakan bahwa budaya Jawa menjadi budaya dominan yang mempengaruhi perilaku manusia Indonesia (Kanungo dan
Medonca, 1996 yang dikutip Audry, 2010). Magnis Suseno (1997) mengatakan bahwa untuk menjaga harmonisasi sosial, maka suatu hubungan sosial di dalam lingkungan masyarakat Jawa dipengaruhi oleh dua prinsip dasar yang menjelaskan ide-ide orang Jawa tentang kehidupan yang baik, yaitu penghindaran konflik dan rasa menghargai (hormat).

Berdasarkan uraian di atas, maka peneliti tertarik untuk mengambil judul "Pengaruh Orientasi Etis, Equity Sensitivity, dan Budaya Jawa terhadap Perilaku Etis Auditor pada Kantor Akuntan Publik di Yogyakarta”.

\section{METODE PENELITIAN}

\section{Tempat dan Waktu Penelitian}

Penelitian ini dilaksanakan di Kantor Akuntan Publik wilayah Yogyakarta. Waktu penelitian ini dilaksanakan dari bulan Desember 2014 sampai Maret 2015.

\section{Jenis Penelitian}

Jenis penelitian yang digunakan adalah penelitian kausal komparatif. Penelitian kausal komparatif merupakan tipe penelitian dengan karakteristik masalah berupa hubungan sebab-akibat antara dua variabel atau lebih. Peneliti melakukan pengidentifikasian fakta atau peristiwa tersebut sebagai variabel dependen, dan melakukan penyelidikan terhadap variabel- 


\section{JURNAL NOMINAL / VOLUME IV NOMOR 1 / TAHUN 2015}

variabel yang mempengaruhi (variabel independen) (Indriantoro, 1999).

\section{Populasi dan Sampel Penelitian}

Menurut Sugiyono (2012: 61) populasi adalah wilayah generalisasi yang terdiri atas: objek atau subjek yang mempunyai kualitas dan karakteristik tertentu yang ditetapkan oleh peneliti untuk dipelajari dan kemudian ditarik kesimpulannya. Sugiyono (2012: 62) juga mendefinisikan sampel merupakan bagian dari jumlah dan karakteristik yang dimiliki oleh populasi tersebut. Populasi dalam penelitian ini adalah seluruh auditor yang bekerja pada Kantor Akuntan Publik yang ada di Yogyakarta. Jumlah Kantor Akuntan Publik yang terdaftar dan yang diambil untuk penelitian ini sebanyak 11 KAP dengan jumlah auditor 119 orang. Jumlah tersebut merupakan populasi sekaligus sampel yang digunakan dalam penelitian ini.

\section{Definisi Operasional Variabel Penelitian}

a. Variabel Dependen

Variabel dependen sering disebut pula sebagai variabel terikat. Variabel terikat merupakan variabel yang dipengaruh atau menjadi akibat dari adanya variabel bebas (Sugiyono, 2012: 59). Variabel dalam penelitian ini adalah Perilaku Etis Auditor (Y).

Perilaku etis merupakan perilaku yang dilakukan sesuai dengan norma- norma sosial yang diterima secara umum oleh masyarakat sehubungan dengan tindakan-tindakan yang benar dan baik. Perilaku etis ini dapat menentukan kualitas individu. Kemampuan untuk dapat mengidentifikasi perilaku etis dan tidak etis sangat berguna dalam semua profesi termasuk auditor. Pendidikan akuntan yang professional tidak hanya menekankan pengembangan skills dan knowledge saja, tetapi juga standar etis dan komitmen professional. Perilaku Etis Auditor adalah variabel yang menunjukkan perilaku etis auditor dalam etika profesi. Penelitian ini memfokuskan perilaku etis pada faktor-faktor atau substansi kode etik akuntan yang dikembangkan Sihwahjoeni dan Gudono (2000) dengan menggunakan indikator pelaksanaan kode etik, dan penafsiran dan penyempurnaan kode etik.

b. Variabel Independen

Dalam penelitian ini terdapat tiga variabel independen, yaitu Orientasi Etis Idealisme $\quad\left(\mathrm{X}_{1}\right), \quad$ Orientasi $\quad$ Etis Relativisme $\left(\mathrm{X}_{2}\right)$, Equity Sensitivity $\left(\mathrm{X}_{3}\right)$, dan Budaya Jawa $\left(\mathrm{X}_{4}\right)$. Menurut Sugiyono (2012: 59) variabel bebas atau variabel independen adalah variabel yang mempengaruhi atau menjadi sebab timbulnya variabel terikat (variabel dependen).

Orientasi etis diartikan sebagai dasar pemikiran untuk menentukan sikap, arah 


\section{JURNAL NOMINAL / VOLUME IV NOMOR 1 / TAHUN 2015}

dan sebagainya secara tepat dan benar yang berkaitan dengan dilema etis. Sebagaimana telah disebutkan bahwa orientasi etis ini diklasifikasikan menjadi idealisme dan relativisme. Orientasi etis idealisme lebih mengacu pada tindakan individu yang harus sesuai dengan nilainilai moral yang berlaku. Sedangkan relativisme merupakan suatu sikap penolakan terhadap nilai-nilai moral yang absolut.

Equity sensitivity merupakan suatu persepsi seseorang terhadap keadilan dengan membandingkan antara inputs dan outcomes yang diperoleh dari orang lain. Husemen (1987) membagi persepsi individu terhadap equity dan inequity dalam tiga kategori yakni: benevolents, equity sensitivities, dan entitleds. Individu benevolent cenderung berperilaku murah hati dan lebih senang memberi daripada menerima. Individu equity sensitivities digambarkan sebagai individu yang memiliki keseimbangan antara inputs dan outcomes. Sedangkan individu entitled digambarkan sebagai individu yang lebih senang menerima lebih daripada memberi.

Budaya Jawa merupakan budaya yang cenderung mempunyai ciri menjunjung tinggi nilai harmoni. Budaya Jawa mengutamakan keseimbangan, keselarasan dan keserasian dalam kehidupan sehari hari. Budaya Jawa menjunjung tinggi kesopanan dan kesederhanaan. Dua prinsip yang mendasari budaya Jawa adalah penghindaran konfik dan rasa menghormati (respect).

\section{Instrumen Penelitian}

Instrumen penelitian merupakan alat ukur yang digunakan dalam melakukan penelitian. Instrumen penelitian yang digunakan dalam penelitian ini ialah Perilaku Etis Auditor dengan indikator yang berupa: pelaksanaan kode etik, dan penafsiran dan penyempurnaan kode. Indikator Orientasi Etis Idealisme meliputi: Suatu tindakan tidak boleh merugikan orang lain, seseorang tidak boleh mengancam kehormatan dan kesejahteraan orang lain, tindakan yang dilakukan sesuai dengan norma universal, dan tindakan moral adalah sesuai dengan tindakan yang sifatnya ideal. Indikator Orientasi Etis Idealisme meliputi: aturan etika berbeda pada setiap komunitas, prinsip moral dipandang sebagai sesuatu yang sifatnya subyektif, penetapan aturan etika secara tegas akan menciptakan hubungan manusia yang lebih baik, dan kebohongan dinilai bermoral atau tidak tergantung pada situasi yang mengelilinginya. Equity Sensitivity indikatornya berupa: benevolents dan entitleds. Indikator Budaya Jawa meliputi: penghindaran konflik dan rasa menghormati (respect). Instrumen Orientasi Etis 
JURNAL NOMINAL / VOLUME IV NOMOR 1 / TAHUN 2015

Idealisme, Orientasi Etis Relativisme, Equity Sensitivity, Budaya Jawa, dan Perilaku Etis Auditor menggunakan modifikasi skala likert 1 sampai 4.

\begin{tabular}{|c|c|c|c|c|}
\hline No. & Variabel & $\begin{array}{c}\text { Jumlah } \\
\text { Butir }\end{array}$ & $\begin{array}{l}\text { Butir } \\
\text { yang } \\
\text { Tidak } \\
\text { Valid }\end{array}$ & $\begin{array}{l}\text { Jumlah } \\
\text { Butir } \\
\text { Valid }\end{array}$ \\
\hline 1 & $\begin{array}{l}\text { Perilaku } \\
\text { Etis }\end{array}$ & 11 & - & 11 \\
\hline 2 & $\begin{array}{l}\text { Orientasi } \\
\text { Etis } \\
\text { Idealisme }\end{array}$ & 10 & - & 10 \\
\hline 3 & $\begin{array}{l}\text { Orientasi } \\
\text { Etis } \\
\text { Relativisme }\end{array}$ & 10 & - & 10 \\
\hline 4 & $\begin{array}{l}\text { Equity } \\
\text { Sensitivity }\end{array}$ & 12 & - & 12 \\
\hline 5 & $\begin{array}{l}\text { Budaya } \\
\text { Jawa }\end{array}$ & 14 & - & 14 \\
\hline & Total & 57 & & 57 \\
\hline
\end{tabular}

\section{Teknik Pengumpulan Data}

Teknik pengumpulan data dilakukan melalui survai dengan menggunakan kuesioner. Survai ini merupakan teknik untuk memperoleh data primer dengan cara menyebarkan kuesioner. Kuesioner merupakan metode pengumpulan data yang dilakukan dengan cara memberikan seperangkat pertanyaan atau pernyataan tertulis kepada responden untuk di jawab. Kuesioner dibagikan secara langsung kepada responden yakni auditor yang berada pada Kantor Akuntan Publik di Yogyakarta.

\section{Uji Instrumen Penelitian}

a. Uji Validitas

Uji validitas digunakan untuk mengukur sah atau valid tidaknya suatu kuesioner. Suatu kuesioner akan dikatakan valid apabila pertanyaan pada kuesioner mampu mengungkapkan sesuatu yang akan diukur oleh kuesioner tersebut (Imam Gozali, 2011: 52). Hasil Uji Validitas Instrumen Penelitian:

b. Uji Reliabilitas

Uji reliabilitas merupakan alat untuk mengukur suatu kuesioner yang merupakan indikator dari variabel atau konstruk. Kuesioner dikatakan reliabel atau handal ketika jawaban seseorang terhadap pertanyaan adalah konsisten atau stabil dari waktu ke waktu (Imam Gozali, 2011: 47). Hasil Uji Reliabilitas Instrumen Penelitian: 
JURNAL NOMINAL / VOLUME IV NOMOR 1 / TAHUN 2015

\begin{tabular}{llccc}
\hline No & Variabel & $\begin{array}{c}\text { Cronbach } \\
\text { Alpha }\end{array}$ & $\begin{array}{l}\text { Krite- } \\
\text { ria }\end{array}$ & Ket. \\
& & 0,856 & 0,7 & Reli \\
\hline 1 & Perilaku & & & abel \\
& Etis & & & Reli \\
\hline 2 & Orientasi & 0,800 & 0,7 & abel \\
& Etis & & & \\
& Idealisme & & & Reli \\
& Orientasi & 0,880 & 0,7 & abel \\
& Etis & & & \\
& Relativisme & & & Reli \\
\hline 4 & Equity & 0,804 & 0,7 & abel \\
& Sensitivity & & & Reli \\
\hline 5 & Budaya & 0,805 & 0,7 &
\end{tabular}

secara signifikan. Dua variabel dikatakan mempunyai hubungan yang linear bila signifikansinya kurang dari 0,05 (Gendro Wiyono, 2011). Hasil pengujian linearitas:

\begin{tabular}{ccc}
\hline $\begin{array}{c}\text { Hubungan } \\
\text { Variabel }\end{array}$ & Linearitas & Keterangan \\
\hline$\left(\mathrm{X}_{1}\right)-(\mathrm{Y})$ & 0,016 & Linear \\
\hline$\left(\mathrm{X}_{2}\right)-(\mathrm{Y})$ & 0,001 & Linear \\
\hline$\left(\mathrm{X}_{3}\right)-(\mathrm{Y})$ & 0,000 & Linear \\
\hline$\left(\mathrm{X}_{4}\right)-(\mathrm{Y})$ & 0,000 & Linear \\
\hline
\end{tabular}

b. Uji Heteroskedastisitas

\section{Teknik Analisis Data}

Teknik analisis data dalam penelitian ini yaitu: 1) uji asumsi klasik, dimana uji yang digunakan adalah uji linearitas, uji heteroskedastisitas, dan uji multikolinearitas, 2) uji hipotesis, dimana uji yang digunakan adalah analisis regresi linear sederhana dan analisis regresi linear berganda.

\section{HASIL PENELITIAN DAN \\ PEMBAHASAN}

\section{Uji Asumsi Klasik}

a. Uji Linearitas

Uji linearitas bertujuan untuk mengetahui apakah variabel-variabel penelitian yang digunakan mempunyai hubungan yang linear ataukah tidak 
JURNAL NOMINAL / VOLUME IV NOMOR 1 / TAHUN 2015

\begin{tabular}{lcl}
\hline \multicolumn{1}{c}{ Variabel } & Sig & \multicolumn{1}{c}{ Keterangan } \\
\hline Orientasi & 0,142 & $\begin{array}{l}\text { Tidak terjadi } \\
\text { heteroskedastisitas }\end{array}$ \\
Etis & & \\
Idealisme & & \\
\hline Orientasi & 0,267 & $\begin{array}{l}\text { Tidak terjadi } \\
\text { heteroskedastisitas }\end{array}$ \\
Etis & & \\
Relativisme & & Tidak terjadi \\
\hline Equity & 0,076 & heteroskedastisitas \\
Sensitivity & & Tidak terjadi \\
\hline Budaya & 0,604 & heteroskedastisitas \\
Jawa & & \\
\hline
\end{tabular}

\begin{tabular}{lccl}
\hline \multirow{2}{*}{ Variabel } & \multicolumn{2}{c}{ Perhitungan } & \multirow{2}{*}{ Keterangan } \\
\cline { 2 - 3 } & Tole- & VIF & \\
& rance & & \\
\hline Orientasi & 0,830 & 1,205 & Tidak terjadi \\
Etis & & & multiko- \\
Idealisme & & & linearitas \\
\hline Orientasi & 0,660 & 1,515 & Tidak terjadi \\
Etis & & & multiko- \\
Relativisme & & & linearitas \\
\hline Equity & 0,552 & 1,811 & Tidak terjadi \\
Sensitivity & & & multiko- \\
& & & linearitas \\
\hline Budaya & 0,669 & 1,494 & Tidak terjadi \\
Jawa & & & multiko- \\
& & & linearitas \\
& & &
\end{tabular}

untuk mendeteksi gejala korelasi antara variabel independen yang satu dengan variabel independen yang lain. Jika VIF $<10$ dan nilai Tolerance > 0,1 maka model dapat dikatakan terbebas dari multikolinearitas dan dapat digunakan dalam penelitian (Imam Ghozali, 2011:106). Hasil pengujian multikolinearitas:

\section{Uji Hipotesis}

a. Analisis Regresi Sederhana

1) Terdapat Pengaruh Orientasi Etis Idealisme terhadap Perilaku Etis Auditor

Berikut ini hasil perhitungan hipotesis 1:

\begin{tabular}{lcccc}
\hline Variabel & $\begin{array}{c}\text { Koefi- } \\
\text { sien }\end{array}$ & $\mathrm{t}$ & $\mathrm{t}$ tabel & Sig \\
& $\begin{array}{l}\text { Regresi } \\
\end{array}$ & & & \\
\hline Konstanta & 14,975 & & & \\
\hline Orientasi & 0,660 & 2,601 & 2,035 & 0,013 \\
Etis & & & & \\
Idealisme & & & & \\
\hline
\end{tabular}

Adjusted R Square : 0,135 


\section{JURNAL NOMINAL / VOLUME IV NOMOR 1 / TAHUN 2015}

Berdasarkan perhitungan regresi linear sederhana yang ditunjukkan tabel di atas, maka persamaan garis regresi untuk hipotesis 1 adalah $\mathrm{Y}=14,975+$ $0,660 X_{1}$. Nilai $r^{2}$ sebesar 0,135 hal ini menunjukkan $13,5 \%$ Perilaku Etis Auditor dipengaruhi oleh Orientasi Etis Idealisme, sedangkan sisanya sebesar $86,5 \%$ dipengaruhi oleh variabel lain di luar penelitian ini. Uji $\mathrm{t}$ statistik untuk variabel Orientasi Etis Idealisme menghasilkan nilai signifikan 0,013 yang berarti lebih kecil dari nilai 0,05 , sehingga dapat disimpulkan bahwa hipotesis pertama diterima.

Hasil penelitian ini mendukung hasil penelitian yang dilakukan oleh Audry (2010) yang menyimpulkan Orientasi Etika Idealisme berpengaruh positif terhadap Perilaku Etis Auditor. Seseorang auditor yang memiliki sikap idealisme akan menemukan adanya masalah etika dan dalam memutuskan suatu tindakan lebih mengarah pada pedoman atau aturan yang telah ditetapkan sebelumnya sehingga akan berperilaku etis. Seorang auditor yang idealis akan melaksanakan pekerjaan profesionalnya mengacu pada aturan atau nilai moral yang berlaku, tanpa sedikitpun keluar dari aturan atau nilai moral tersebut. Hasil penelitian ini mengindikasikan bahwa terdapat pengaruh Orientasi Etis Idealisme terhadap Perilaku Etis Auditor.

2) Terdapat Pengaruh Orientasi Etis Relativisme terhadap Perilaku Etis Auditor

Berikut ini hasil perhitungan hipotesis 2:

\begin{tabular}{lcccc}
\hline Variabel & $\begin{array}{c}\text { Koefi- } \\
\text { sien } \\
\text { Regresi }\end{array}$ & $\begin{array}{c}\mathrm{t} \\
\text { hitung }\end{array}$ & $\begin{array}{c}\mathrm{t} \\
\text { tabel }\end{array}$ & Sig \\
& & & \\
\hline Konstanta & 51,130 & & & \\
\hline Orientasi & $-0,589$ & - & 2,035 & 0,001 \\
Etis & & 3,438 & & \\
Relativisme & & & & \\
\hline & & Adjusted $R$ Square $: 0,226$ \\
\end{tabular}

Berdasarkan perhitungan regresi linear sederhana yang ditunjukkan tabel di atas, maka persamaan garis regresi untuk hipotesis 2 adalah $\mathrm{Y}=51,130$ $0,589 X_{2}$. Nilai $r^{2}$ sebesar 0,226 hal ini menunjukkan 22,6\% Perilaku Etis Auditor dipengaruhi oleh Orientasi Etis Relativisme, sedangkan sisanya sebesar $77,4 \%$ dipengaruhi oleh variabel lain di 
JURNAL NOMINAL / VOLUME IV NOMOR 1 / TAHUN 2015

luar penelitian ini. Uji t statistik untuk variabel Orientasi Etis Relativisme menghasilkan nilai signifikansi 0,001 yang berarti lebih kecil dari nilai 0,05 , sehingga dapat disimpulkan bahwa hipotesis kedua diterima.

Hasil penelitian ini mendukung hasil penelitian yang dilakukan oleh Revita Mardani (2014) yang menyimpulkan bahwa relativisme berpengaruh positif terhadap persepsi mahasiswa akuntansi atas perilaku tidak etis akuntan. Orang yang mempunyai karakteristik relativisme cenderung akan setuju atau mentolelir terhadap perilaku tidak etis yang terjadi, sehingga mempunyai kemungkinan untuk melakukan perilaku tidak etis. Penelitian ini juga mendukung penelitian Falah (2006) yang secara spesifik menemukan bahwa relativisme berpengaruh terhadap sensitivitas etika. Dimana sensitivitas etika merupakan kemampuan untuk menyadari adanya nilai-nilai etika dalam suatu keputusan yang akan mengacu pula pada perilaku etis auditornya. Hasil penelitian ini mengindikasikan bahwa terdapat pengaruh Orientasi Etis Relativisme terhadap Perilaku Etis Auditor.
3) Terdapat pengaruh Equity sensitivity terhadap Perilaku Etis Auditor

Berikut ini hasil perhitungan hipotesis 3:

\begin{tabular}{lcccc}
\hline Variabel & $\begin{array}{c}\text { Koefisien } \\
\text { Regresi }\end{array}$ & $\begin{array}{c}\mathrm{t} \\
\text { hitung }\end{array}$ & $\begin{array}{c}\mathrm{t} \\
\text { tabel }\end{array}$ & Sig \\
\hline Konstanta & 9,446 & & & \\
\hline Equity & 0,729 & 7,306 & 2,035 & 0,000 \\
Sensitivity & & & & \\
\hline
\end{tabular}

Adjusted R Square : 0,586

Berdasarkan perhitungan regresi linear sederhana yang ditunjukkan tabel di atas, maka persamaan garis regresi untuk hipotesis 3 adalah $\mathrm{Y}=9,446+$ $0,729 X_{3}$. Nilai $r^{2}$ sebesar 0,586 hal ini menunjukkan 58,6\% Perilaku Etis Auditor dipengaruhi oleh Equity Sensitivity, sedangkan sisanya sebesar $41,4 \%$ dipengaruhi oleh variabel lain di luar penelitian ini. Uji t statistik untuk variabel Equity Sensitivity menghasilkan nilai signifikansi 0,000 yang berarti lebih kecil dari nilai 0,05, sehingga dapat disimpulkan bahwa hipotesis ketiga diterima.

Hasil penelitian ini mendukung penelitian Putri Nugrahaningsih (2005) yang menyebutkan secara 


\section{JURNAL NOMINAL / VOLUME IV NOMOR 1 / TAHUN 2015}

statistik, auditor benevolents cenderung mempunyai perilaku etis daripada auditor entitleds. Namun, penelitian ini membantah hasil penelitian yang dilakukan oleh Jurica dan Gunardi (2012) yang menyimpulkan bahwa equity sensitivity tidak berpengaruh terhadap perilaku etis mahasiswa akuntansi Universitas Bakrie. Hasil penelitian ini mengindikasikan bahwa terdapat pengaruh Equity Sensitivity terhadap Perilaku Etis Auditor.

4) Terdapat pengaruh Budaya Jawa terhadap Perilaku Etis Auditor

Berikut ini hasil perhitungan hipotesis 4:

\begin{tabular}{lcccc}
\hline Variabel & $\begin{array}{c}\text { Koefisien } \\
\text { Regresi }\end{array}$ & $\begin{array}{c}\mathrm{t} \\
\text { hitung }\end{array}$ & $\begin{array}{c}\mathrm{t} \\
\text { tabel }\end{array}$ & Sig \\
\hline Konstanta & 8,833 & & & \\
\hline $\begin{array}{l}\text { Budaya } \\
\text { Jawa }\end{array}$ & 0,608 & 4,545 & 2,035 & 0,000 \\
& & & & \\
\hline
\end{tabular}

Adjusted R Square : 0,347

Berdasarkan perhitungan regresi linear sederhana yang ditunjukkan tabel di atas, maka persamaan garis regresi untuk hipotesis 4 adalah $\mathrm{Y}=8,833+$ $0,608 X_{4}$. Nilai $r^{2}$ sebesar 0,347 hal ini menunjukkan 34,7\% Perilaku Etis Auditor dipengaruhi oleh Budaya Jawa, sedangkan sisanya sebesar $65,3 \%$ dipengaruhi oleh variabel lain di luar penelitian ini. Uji $t$ statistik untuk variabel Budaya Jawa menghasilkan nilai signifikansi 0,000 yang berarti lebih kecil dari nilai 0,05, sehingga dapat disimpulkan bahwa hipotesis keempat diterima.

Hasil penelitian ini mendukung hasil penelitian yang dilakukan oleh Audry (2010) yang menyimpulkan bahwa Budaya Jawa berpengaruh positif terhadap Perilaku Etis Auditor. Auditor yang berasal dari jawa dan memegang teguh prinsip-prinsip dalam budaya Jawa akan cenderung mengembangkan perilaku etis. Hasil penelitian ini mengindikasikan bahwa terdapat pengaruh Budaya Jawa terhadap Perilaku Etis Auditor.

5) Terdapat pengaruh Orientasi Etis Idealisme, Orientasi Etis Relativisme, Equity Sensitivity, dan Budaya Jawa secara simultan terhadap Perilaku Etis Auditor Berikut ini hasil perhitungan hipotesis 5: 
JURNAL NOMINAL / VOLUME IV NOMOR 1 / TAHUN 2015

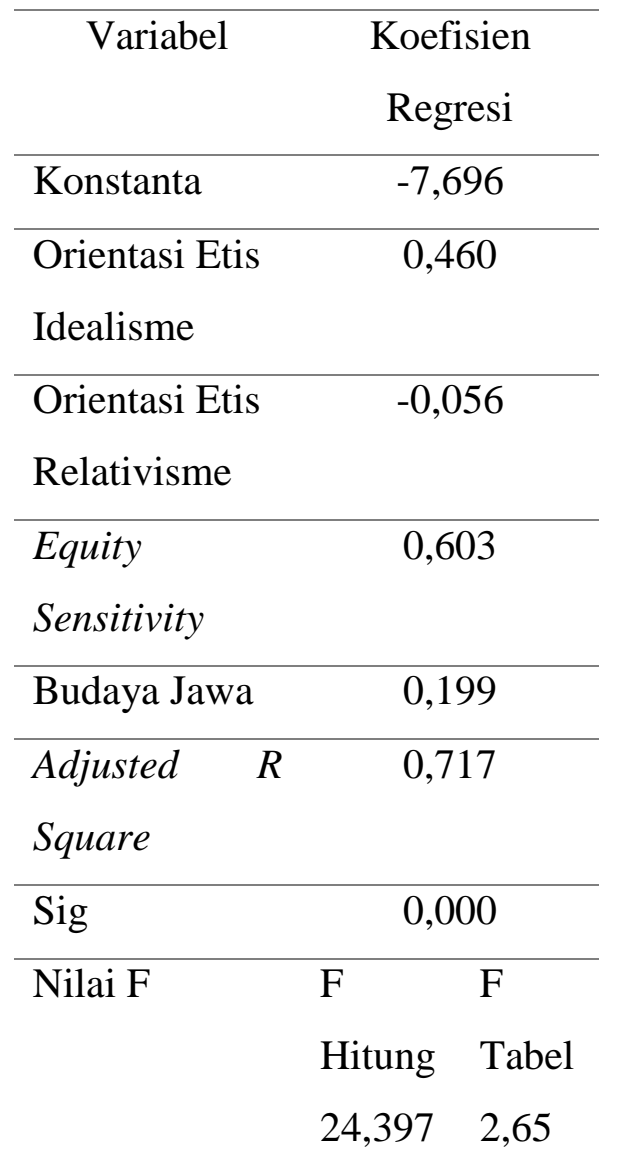

Berdasarkan perhitungan regresi linear sederhana yang ditunjukkan tabel di atas, maka persamaan garis regresi untuk hipotesis 5 adalah $\mathrm{Y}=-7,696+$ $0,460 \quad X_{1}-0,056 \quad X_{2}+0,603 \quad X_{3}+$ $0,199 \mathrm{X}_{4}$. Nilai $\mathrm{R}^{2}$ sebesar 0,717 hal ini menunjukkan $71,7 \%$ perilaku etis auditor dipengaruhi oleh Orientasi Etis Idealisme, Orientasi Etis Relativisme, Equity Sensitivity, dan Budaya Jawa secara simultan, sedangkan sisanya sebesar $28,3 \%$ dipengaruhi oleh variabel lain di luar penelitian ini. Setelah dilakukan uji signifikansi dengan uji $\mathrm{F}$ diperoleh nilai $\mathrm{F}_{\text {hitung }}$ sebesar 24,397 lebih besar dari $F_{\text {tabel }}$ yaitu 2,65. Uji F statistik untuk variabel independensi menghasilkan nilai signifikansi 0,000 yang berarti lebih kecil dari nilai 0,05, sehingga dapat disimpulkan bahwa hipotesis kelima diterima. Perilaku etis audit sangat diperlukan oleh auditor sebagai pedomannya dalam pengambilan keputusan audit. Beberapa faktor dapat mempengaruhi perilaku etis yang dilakukan oleh auditor. Pertama, orientasi etis yang dikendalikan oleh dua karakteristik yaitu relativisme dan idealisme. Kedua, equity sensitivity yang menggambarkan keseimbangan antara inputs dan outcomes. Ketiga, budaya Jawa yang mempunyai prinsip penghindaran konflik dan rasa menghormati. Dari beberapa faktor tersebut yakni orientasi etis, equity sensitivity dan budaya Jawa auditor dimungkinkan memberikan pengaruh terhadap perilaku etis audit.

Hasil penelitian ini mengindikasikan bahwa terdapat pengaruh Orientasi Etis Idealisme, Orientasi Etis Relativisme, Equity Sensitivity, dan Budaya Jawa secara 


\section{JURNAL NOMINAL / VOLUME IV NOMOR 1 / TAHUN 2015}

simultan berpengaruh terhadap Perilaku Etis Auditor.

\section{SIMPULAN DAN SARAN}

\section{Simpulan}

Berdasarkan analisis data peneliti, maka kesimpulan yang dapat diambil dalam penelitian ini adalah:

a. Terdapat pengaruh Orientasi Etis Idealisme terhadap Perilaku Etis Auditor pada Kantor Akuntan Publik di Yogyakarta. Hal ini dibuktikan melalui analisis regresi sederhana diperoleh nilai $\mathrm{r}^{2}$ sebesar 0,135 , dapat diartikan besarnya pengaruh Orientasi Etis Idealisme terhadap Perilaku Etis Auditor yaitu 13,5\%. Hasil uji t statistik menghasilkan nilai signifikansi lebih kecil dari level of significant $(0,013<$ 0,050). Besarnya nilai koefisien regresi $\mathrm{X}_{1}$ 0,660 dan bilangan konstantanya 14,975. Persamaan garis regresinya adalah $\mathrm{Y}=14,975+0,660 \mathrm{X}_{1}$

b. Terdapat pengaruh Orientasi Etis Relativisme terhadap Perilaku Etis Auditor pada Kantor Akuntan Publik di Yogyakarta. Hal ini dibuktikan melalui analisis regresi sederhana diperoleh nilai $r^{2}$ sebesar 0,226, dapat diartikan besarnya pengaruh Orientasi Etis Relativisme terhadap Perilaku Etis Auditor yaitu 22,6\%. Hasil uji t statistik menghasilkan nilai signifikansi lebih kecil dari level of significant $(0,001<$
0,050). Besarnya nilai koefisien regresi $\mathrm{X}_{2}-0,589$ dan bilangan konstantanya 51,130. Persamaan garis regresinya adalah $\mathrm{Y}=51,130-0,589 \mathrm{X}_{2}$.

c. Terdapat pengaruh Equity sensitivity terhadap Perilaku Etis Auditor pada Kantor Akuntan Publik di Yogyakarta. Hal ini dibuktikan melalui analisis regresi sederhana diperoleh nilai $\mathrm{r}^{2}$ sebesar 0,586, dapat diartikan besarnya pengaruh Equity Sensitivity terhadap Perilaku Etis Auditor yaitu 58,6\%. Hasil uji $\mathrm{t}$ statistik menghasilkan nilai signifikansi lebih kecil dari level of significant $(0,000<0,050)$. Besarnya nilai koefisien regresi $X_{3} \quad 0,729$ dan bilangan konstantanya 9,446. Persamaan garis regresinya adalah $\mathrm{Y}=$ $9,446+0,729 X_{3}$.

d. Terdapat pengaruh Budaya Jawa terhadap Perilaku Etis Auditor pada Kantor Akuntan Publik di Yogyakarta. Hal ini dibuktikan melalui analisis regresi sederhana diperoleh nilai $\mathrm{r}^{2}$ sebesar 0,347, dapat diartikan pula besarnya pengaruh Budaya Jawa terhadap Perilau Etis Auditor yaitu 34,7\%. Hasil uji F statistik menghasilkan nilai signifikansi lebih kecil dari level of significant $(0,000<$ 0,050). Besarnya nilai koefisien regresi $\mathrm{X}_{4}$ 0,608 dan bilangan konstantanya 8,833 . Persamaan garis regresinya adalah $\mathrm{Y}=8,833+0,608 \mathrm{X}_{4}$ 


\section{JURNAL NOMINAL / VOLUME IV NOMOR 1 / TAHUN 2015}

e. Terdapat pengaruh Orientasi Etis Idealisme, Orientasi Etis Relativisme, Equity Sensitivity, dan Budaya Jawa secara simultan terhadap Perilaku Etis Auditor. Hal ini dibuktikan melalui analisis regresi berganda didapatkan nilai $\mathrm{R}^{2}$ sebesar 0,717 atau memiliki arti Orientasi Etis Idealisme, Orientasi Etis Relativisme, Equity Sensitivity, dan Budaya Jawa mempunyai pengaruh terhadap Perilaku Etis Auditor sebesar $71,7 \%$. Selain itu signifikansi lebih kecil dari pada level of significant $(0,000<0,050)$. Persamaan garis regresinya adalah $\mathrm{Y}=-7,696+0,460$ $X_{1}-0,056 X_{2}+0,603 X_{3}+0,199 X_{4}$.

\section{Saran}

Berdasarkan hasil penelitian serta halhal yang terkait dengan keterbatasan penelitian ini, maka dapat diberikan saransaran sebagai berikut:

a. Untuk meminimalisasi bias akibat dari sedikitnya responden dan agar hasil penelitian dapat digunakan untuk generalisasi, maka penelitian sebaiknya dilakukan dalam cakupan yang lebih luas yakni dengan menambah jumlah sampel penelitian dan memperluas wilayah sampel penelitian, bukan hanya di wilayah Yogyakarta tetapi juga di kota-kota lainnya.

b. Penelitian selanjutnya, perlu menambahkan faktor-faktor penjelas lain untuk dapat menjelaskan perilaku etis auditor dari sudut pandang lain dengan lebih baik. Dengan menambahkan faktor-faktor lain yang dijadikan sebagai variabel independen, yang dapat menjelaskan perilaku etis auditor dengan lebih baik kedalam model penelitian ini.

c. Penelitian selanjutnya diharapkan dapat menambah variabel moderasi yang dapat memperkuat atau memperlemah variabel independen terhadap variabel dependen (Perilaku Etis Auditor).

d. Penelitian selanjutnya agar lebih memperhatikan waktu penelitian. Waktu penelitian diharapkan tidak dilakukan pada waktu sibuk auditor sehingga tingkat pengembalian kuesioner dapat lebih tinggi.

e. Bagi auditor sebaiknya dalam memutuskan suatu tindakan harus berdasarkan prinsip-prinsip etika moralnya, dimana perbuatan yang bermoral itu tidak menimbang positif atau negatifnya. Dengan demikian, auditor akan lebih berperilaku etis dalam melaksanakan pekerjaannya.

f. Auditor seharusnya meyakini bahwa prinsip-prinsip etika merupakan hal yang penting untuk dijadikan bagian dari kode etik. Dimana prinsip-prinsip etika tersebut akan menjadi pedoman dalam menjalankan tugasnya, sehingga ketika seorang auditor sudah 


\section{JURNAL NOMINAL / VOLUME IV NOMOR 1 / TAHUN 2015}

melaksanakan sesuai dengan etika yang ada maka ia akan lebih berperilaku etis.

g. Auditor dalam melaksanakan pekerjaan profesional hendaknya tidak hanya memikirkan kepuasannya saja ketika bisa mendapatkan sesuatu dari tempat kerja. Tetapi ia juga harus memikirkan bagaimana memberikan kontribusi dalam menyelesaikan tugasnya dengan baik.

h. Apabila seorang auditor mempunyai perbedaan pendapat dengan pimpinan, hendaknya menyampaikan pendapatnya dengan cara yang baik kepada pimpinannya tanpa menimbulkan konflik. Musyawarah bersama dalam memecahkan masalah akan menghasilkan keputusan yang lebih baik.

\section{DAFTAR PUSTAKA}

Adji Praktikto. (2012). "Pengaruh Budaya Terhadap Kinerja Perekonomian. Buletin Studi Ekonomi”. Vol, 17 No.2:98-115.

Al Haryono Jusup. (2001). Auditing ( Pengauditan ). Yogyakarta : STIE YKPN.

Alvin. A. Arens, James. K. Loebbecke. (2003). Auditing Pendekatan Terpadu. (Alih bahasa oleh Yusuf. A. A.). Jakarta: Salemba Empat.

Arianti. (2012). “Analisis Perbedaan Perilaku Etis Auditor Dalam Etika
Profesi (Studi Terhadap Peran Faktor-

Faktor Individual: Locus of Control, Job Experience, Dan Gender)". Skripsi. Universitas Hasanuddin Makassar.

Audry Leiwakabessy. (2010). "Pengaruh Orientasi Etis dan Budaya Jawa terhadap Perilaku Etis Auditor”. Jurnal Maksi. Vol 10 No.1 Januari 2010: 115.

Aziza dan Salim. (2008). "Pengaruh Orientasi Etika pada Komitmen dan Sensitivitas Etika Auditor". SNA 11 Pontianak.

Erna Hendrawati. (2011). “ Independensi Auditor dalam Perpektif Prinsip Penghindaran Konflik dan Prinsip Penghargaan pada Budaya Jawa". Swastika Jurnal Ekonomi, Sains, dan Pendidikan.Vol 3 No. 1 Mei 2011: 4862.

Fatmawati, N. D. (2007). “Analisis Pengaruh Faktor-faktor Individual terhadap Perilaku Etis Auditor di KAP (Survey pada Auditor di Kantor Akuntan Publik Yogayakarta dan Surakarta)”. Skripsi. Surakarta: Universitas Muhammadyah Surakarta. Forsyth, D. R., (1980). “A Taxonomy of Ethical Ideologies". Journal of Personality and Social Psychology. Vol 39. pp. 175-184.

Gendro Wiyono. (2011). Merancang Penelitian Bisnis dengan alat analisis 


\section{JURNAL NOMINAL / VOLUME IV NOMOR 1 / TAHUN 2015}

SPSS 17.0 \& SmartPLS 2.0 Edisi 1.

Yogyakarta: UPP STIM YKPN.

Herawati dan Susanto. (2009). "Pengaruh

Profesionalisme, Pengetahuan dan

Etika Profesi terhadap Pertimbangan

Tingkat Materialitas Akuntan Publik".

Jurnal Akuntansi dan Keuangan

Vol.11 No.1

Higgins dan Kelleher. (2005). Comparative

Perspectives on the Ethical

Orientations of Human Resources,

Marketing and Finance Functional

Managers. Journal of Business Ethics, Vol.56, pp. 275-288.

Husemen, R. C., Hatfield, J. D., \& Miles, E.

W. (1987). A New Perspective on

Equity Theory: The Equity Sensitivity

Construct. Academy of Management

Review, Vol.12: 222-234.

Ihyaul Ulum M.D. (2009). Audit Sektor

Publik, Suatu Pengantar. Jakarta: PT Bumi Aksara.

Imam Ghozali. (2011). Aplikasi Analisis

Multivariat Dengan Program IBM

SPSS 19. Semarang: UNDIP.

Indriantoro, Nur, dan Bambang. (1999).

Metodologi Penelitian Bisnis Untuk Akuntansi dan Manajemen.

Yogyakarta: BPFE.

Khomsiyah dan Nur Indriantoro. (1998).

"Pengaruh Orientasi Etika terhadap

Komitmen, dan Sensitivitas Etika

Akuntan publik Pemerintah di DKI
Jakarta". Jurnal Riset Akuntansi

Indonesia Vol 1 (1) Jan: 13-28.

Khairul Bahrun. (2002). "Analisis Pengaruh

Dimensi Nilai Budaya terhadap Sikap

Komitmen Organisasional dan

Kepuasan Kerja Karyawan”. Thesis.

Semarang: Universitas Diponegoro.

Lia Nurfarida. (2011). "Pengaruh Budaya

Etis Organisasi dan Orientasi Etika Terhadap Komitmen Organisasi dan Sensitivitas Etika Auditor". Skripsi. Jakarta: UIN Syarif Hidayatullah.

Lucyanda, J. \& Endro, G. (2012). "Faktor-

Faktor Yang Memengaruhi Perilaku Etis Mahasiswa Akuntansi Universitas Bakrie”. Media Riset Akuntansi, Vol 2: $113-142$.

M. Khairul Dzakirin. (2013). "Orientasi Idealisme, Relativisme, Tingkat Pengetahuan, dan Gender: Pengaruhnya pada Persepsi Mahasiswa tentang Krisis Etika Akuntan Profesional". Universitas Brawijaya.M. Syarifuddin. (2005) Kasus Mulyana dalam Perspektif Etika, Suara Merdeka. April hal.6.

Mulyadi. (2002). Auditing. Edisi Ke Enam. Jakarta : Salemba Empat.

Poerhadiyanto dan Sawarjuwono. (2002). "Menegakkan Independensi Auditor dari Pengaruh Budaya Jawa: Tata Krama, Suba Sita, Gelagat Pasemon”. Simposium 


\section{JURNAL NOMINAL / VOLUME IV NOMOR 1 / TAHUN 2015}

Nasional Akuntansi V Semarang, 56 September.

Putri Nugrahaningsih. (2005). “Analisis Perbedaan Perilaku Etis Auditor di Kantor Akuntan Publik dalam Etika Profesi (Studi terhadap Peran Faktorfaktor individual: Locus of Control, Lama Pengalaman Kerja, Gender, dan Equity Sensitivity)”. Simposium Nasional Akuntansi VIII Solo: 617630.

Ricky Griffin dan Ronald J. Ebert. (2006).

Bisnis Edisi Kedelapan. Jakarta: Erlangga.

Sevrida Verawaty Lamtiurma Purba. (2011).

"Pengaruh Orientasi Etis Terhadap Pertimbangan Etis Auditor dengan Budaya Etis Organisasi sebagai variabel Moderating (studi empiris pada KAP di Semarang)". Skripsi. Semarang: Universitas Diponegoro.

Sihwahjoeni dan Gudono, M. (2000).

"Persepsi Akuntan terhadap Kode Etik Akuntan". Jurnal Riset Akuntansi Indonesia. Vol.3 (2) Juli: 168-184.

Sugiyono. (2009). Metode Penelitian

Kuantitatif, Kualitatif dan $R \& D$.

Bandung: CV Alfabeta. . (2010). Metode Penelitian Bisnis.

Bandung: CV Alfabeta. . (2012). Statistika untuk Penelitian.

Bandung: CV Alfabeta.
Suharsimi Arikunto. (2010). Prosedur Penelitian Suatu Pendekatan Praktik. Jakarta: Rineka Cipta.

Sujamto. (1992). Refleksi Budaya Jawa. Semarang: Dahara Prize

Sumarni dan Wahyuni. (2006). Metodologi Penelitian Bisnis. Yogyakarta: Andi Offset.

Sutrisno Hadi. (2004). Analisis Regresi. Yogyakarta: Andi Offset.

Syaikul Falah. (2006). Pengaruh Budaya Etis Organisasi dan Orientasi Etika terhadap Sensitivitas Etika. SNA X Makasar.

Unti Ludigdo. (2007). Paradoks Etika Akuntan. Yogyakarta: Pustaka Pelajar. Ustadi, N. H., \& Utami, R. D. (2005). "Analisis Perbedaan Faktor-faktor Individual Terhadap Persepsi Perilaku Etis Mahasiswa. Jurnal Akuntansi \& Auditing". Volume 01/No.02/Mei: 162-180.

Velasquez, Manuel G. (2002). Etika Bisnis. Yogyakarta : ANDI.

Weathington, B. L., \& Reddock, C. M. (2011). "Equity Sensitivity in "Fringe" Benefit Value and Satisfaction". Institute of Behavioral and Applied Management. 